\title{
Human immunodeficiency virus disease training: A how to' guide
}

JOYCE M. JOHNSON, DO

As the HIV epidemic spreads throughout the United States, and as an increasing number of persons become infected with the virus and manifest its many complications, more and more physicians are being asked to give presentations on HIV disease to professional and community groups. This is especially true since AIDS education has become a primary prevention tool.

The author provides guidelines for giving a talk on AIDS. The general principles are applicable to presentations both to other health professionals and to lay-community groups. The outline can be varied, and the lecture material can be expanded or summarized to meet the needs of the particular audience. Sources for further information are also provided.

As the human immunodeficiency virus (HIV) epidemic spreads throughout the United States, more and more osteopathic physicians are being asked to give lectures on HIV diseases to various professional and community groups. For many physicians, these lectures have become a part of the regular routine. For

Dr Johnson is board-certified in preventive medicine/ public health and psychiatry.

The ideas in this paper are those of the author, and not necessarily those of St Elizabeth's Hospital, the District of Columbia Commission on Mental Health, or the United States Department of Health and Human Services.

Reprint requests to Joyce M. Johnson, DO, 5518 Western Ave, Chevy Chase, MD 20815. others, particularly those in rural areas, where the HIV epidemic has only recently gained attention, these lectures may be more novel experiences.

Although the number of HIV-infected patients being treated in osteopathic hospitals is increasing, many physicians have had as yet little or no experience with HIV patients. As more hospitals care for these patients, healthcare workers need to become educated about HIV disease. In the hospital setting, the osteopathic physician is frequently asked to give "grand rounds" for house staff, to conduct less formal training sessions for nurses and other staff members, or to educate kitchen or housekeeping employees about appropriate techniques.

With the increase in public interest in AIDS, osteopathic physicians are frequently being asked to give talks about AIDS at church groups, parent-school-association meetings, and other civic gatherings.

Many thoughts, fears, and feelings flash through a physician's mind on being asked to give his or her first presentation on AIDS. Generally, the first question to be dealt with is, should I say "Yes?" After that major step is taken, the presentation must be planned. In this paper nine guidelines are offered for planning a presentation on AIDS.

\section{Clarify the purpose}

The first step in planning a successful AIDS presentation is to clarify the purpose. Generally, the person extending the invitation has 
a specific purpose in mind and some idea about the scope of the talk; these should be ascertained and discussed fully. For example, the purpose may be to train nurses or other staff members about the need for universal infection-control precautions, to help ward staff with psychosocial issues, or to give beginning interns an overview of the disease before they treat their first patients. Each of these presentations should have a different focus. The more information you have about the specific purpose of the talk, the more relevant your talk can become.

If other speakers will be presenting, it is also essential to have a clear idea of the objectives and content of their lectures; this will make it easier for you to prepare a complementary presentation to avoid unnecessary duplication.

\section{Know the audience}

Second, it is important to know who the audience will be. Will it consist of healthcare professionals or the general public? Will the healthcare group consist of intensive-careunit nurses, surgical residents, or laboratory workers? Will the community group be a church organization, parent-teacher association, or some other group? If you know the general nature of the audience, you can plan an understandable seminar to meet its particular needs. In a speech to surgical residents, for example, such issues as infection control and surgical diagnoses would be of interest. In one to a local parent-teacher association, information about AIDS cases in children and adolescents, and about the routes of transmission within these age groups should be discussed.

The audience will determine the choice of words; medical terminology is appropriate for healthcare workers, but nontechnical terminology may be essential for a community group. Defining terms that may be unfamiliar to a given audience will make the lecture more comprehendible.

Knowledge about the audience will help you anticipate the type of questions that may be asked. Healthcare professionals are more likely to ask sophisticated clinical or policy questions, while a lay audience is more likely to focus on issues raised in a recent newspaper article or on other information from the general media.

It is also helpful to find out the approximate size of the audience, since this will have a bearing on the type of presentation you plan. If the audience will be one of eight to ten persons who want to gather information, for example, the format may be an informal questionand-answer session. If it is to be a scientific seminar for 200 physicians, a very different and much more structured presentation will be appropriate.

\section{Identify the topic}

In the short span of about 8 years, the AIDS epidemic has grown from a syndrome whose name was recognized by only a few to an international problem affecting almost everyone. In today's world it is no longer possible to "tell all there is to know about AIDS in 1 hour." In preparing a talk on HIV disease, the subject must be carefully limited, with such factors as the purpose of the talk and the nature and size of the audience taken into consideration. Ideally, you should have a comprehensive understanding of the specific area chosen. Usually, the persons attending a meeting come with certain goals, often nonverbalized. The more you can meet these goals the more interested your audience will be.

The list of possible topics is endless. Tables 1 through 8 provide short outlines of possible topics. Each of these topics could be subdivided into several others. The level of the audience's knowledge about HIV disease will help determine how specific the presentation should be. Healthcare professionals are more likely to prefer a specialized presentation; a lay audience, a more general overview.

\section{Make an outline}

After a specific topic has been selected, a general outline of the presentation can be made. You should identify one to three important points and organize the presentation around them. A well-organized talk will keep listeners alert. A working outline will also serve as a guide for the literature search and other steps that follow. 


\section{Table 1}

Topics for Presentation: Epidemiology of AIDS

- Case definition

What is HIV disease?

What is AIDS?

- Historical perspective, including epidemic curves

- Local and national surveillance data

1. Groups at risk

2. Routes of transmission

3. Incidence and prevalence rates by geographic area

4. Prognosis (case-fatality rates)

\section{Table 2}

Topics for Presentation: Medical Aspects

Signs and symptoms

- Early nonspecific signs and symptoms (weight losś, anorexia, fever, diarrhea, lymphadenopathy, etc)

- AIDS related complex (ARC) and other categories

- AIDS-related opportunistic infections and tumors

Diagnosis

- HIV antibody testing

- Indicators of immune status

- Opportunistic infections and tumors

- Other clinical aspects

Medical treatment

- AZT

- Experimental antivirals, immune modulators, etc

- Treatment of opportunistic infections and tumors

Natural history and prognosis

- HIV infection (asymptomatic)

- AIDS related complex

- AIDS case definition

- Various opportunistic infections and tumors

\section{Collect reference materials}

Information on AIDS can be obtained from numerous sources. The type of presentation will determine the number and types of resources used. For a scientific presentation on HIV disease, a formal literature search (such as the computerized Medline search) may be needed. For an informal discussion, a quick review of your personal resource file may suffice. Several informational sources are listed in the following sections.

\section{Osteopathic publications}

Every osteopathic journal has had at least several articles on AIDS. Currently, JAOA is run-
Table 3

Topics for Presentation: Neuropsychiatric Aspects of Patient Care

Direct neuropsychiatric complications of HIV infection

- Dementia

- Depression

- Other neurotropic effects

Neuropsychiatric sequelae of opportunistic infections and tumors

Treatment issues

- Antidepressants, anxiolytics, and other psychotropic drugs

- Psychotherapy (family, group, individual)

- Use of inpatient, outpatient, and home-care facilities

ning a series of articles on HIV disease, covering a range of topics.

\section{Hospital infection control officers}

Hospital infection control officers should be well versed in the transmission and prevention of HIV disease. They will have a copy of the current hospital infection control policies as well as an understanding of the issues immediately important to their institutions. They will also have copies of the Centers for Disease Control publication Morbidity and Mortality Weekly Report (MMWR), which includes most national AIDS-prevention recommendations along with short articles on current AIDSrelated topics. These articles are often used by newspapers to develop their stories.

\section{Gay men's clinics}

Many cities have a small health center, often a voluntary, nonprofit clinic, which provides care primarily to gay men. Most of these clinics were established to focus on the particular needs of gay men and have evolved into AIDS resource centers. They usually provide anonymous HIV testing, health education, and AIDS treatment or referral, or both. The clinics may also be the community focus for AIDS-counseling groups, AIDS hospices, AIDS "buddies," and other support services. Often they have informal libraries on AIDS-related topics and an assortment of brochures for the public. Their staff members are experts on available community resources. 
Evidence directly linking elevated cholesterol and CAD made you take a closer look at lipid levels

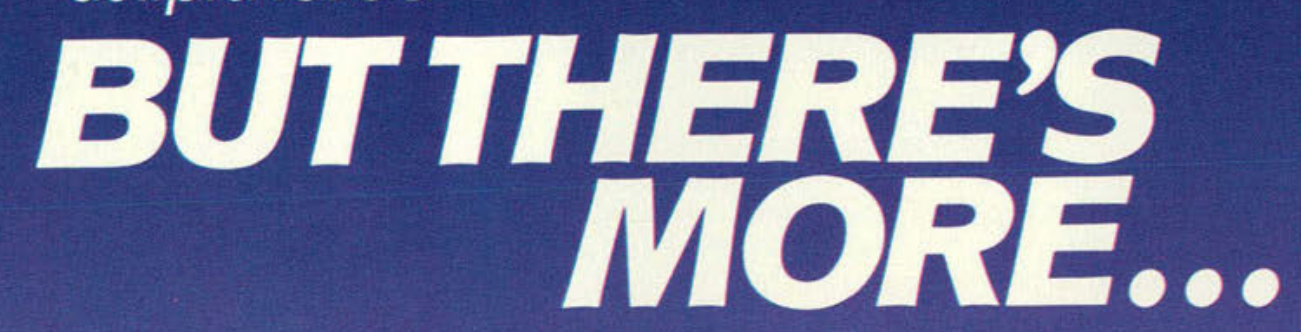



Lorelco is indicated for the reduction of elevated serum cholesterol in patients with primary hypercholesterolemia, as an adjunct to diet.
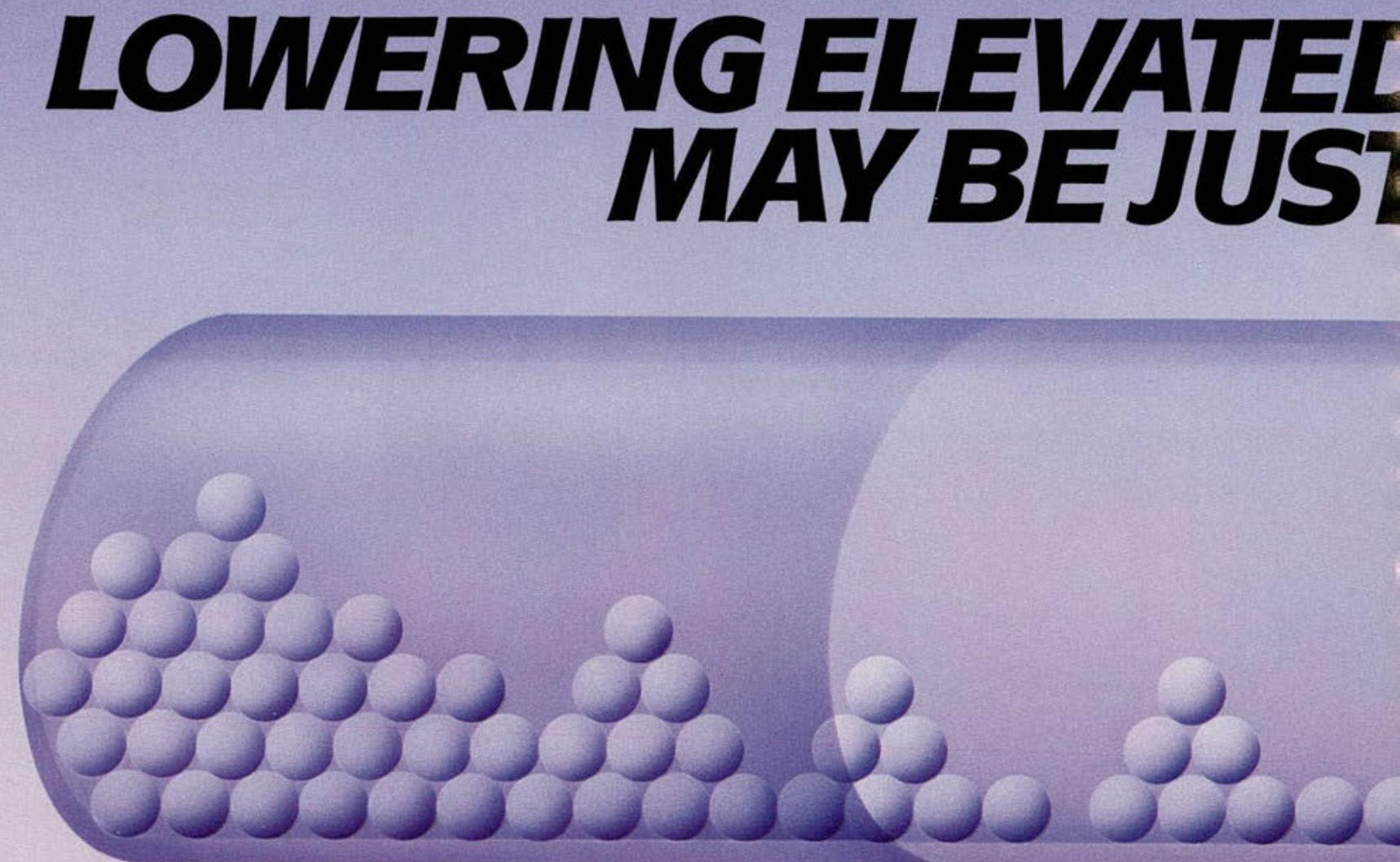

Lorelco (probucol) offers proven longterm cholesterollowering efficacy*

- Reduces total cholesterol by up to $27 \%{ }^{1,2}$

- Maintains lower levels, as proven over a 12-year period ${ }^{3}$

- Provides the assurance of extensive clinical experience

*The effect of probucol-induced reduction of serum cholesterol or triglyceride levels or reduction of $\mathrm{HDL}$-cholesterol levels on morbidity or mortality due to coronary heart disease has not been established.

References: 1. SAfr Med J 1982;62:7-11. 2. Arch Intern Med 1981;141:1428-1432. 3. Data on file, MERRELL DOW PHARMACEUTICALS INC. Cincinnati, Ohio 45242 9553. 4. Am J Cardiol 1988:62:31B-36B. 5. Atherosclerosis 1986:62:209-217 6. Proc Natl Acad Sci USA 1987:84:5928-5931.7. Clin Invest 1986:77:641-644. 8. Proc Natl Acad Sci USA 1987:84:7725-7729 9. Am I Cardiol 1988:62:68-128 8. Proc Nati Acad Sci USA 1987,84:7725-7729. 9. Am J Cardiol 1988,62:68-12B Cardiol 1988:62:668-72B 13. Am J Cardiol 1988:62:73B-768. 14. Am J Cardiol 1988;62:52B-56B.

\section{Lorelco affects cholesterol in unique urays ${ }^{\dagger}$}

- Inhibits the oxidative modification of $L D L^{4-10}$

- Enhances HDL-mediated reverse cholesterol transport $\$ \S$

†Unique modes of action suggested by recel in vitro studies and human and/or animal in vivo data; clinical significance, however, is $r$. yet established.

¥These effects of probucol on LDL-(increase ir abolic rate) and HDL-cholesterol may be linkec observed increased excretion of fecal bile acids final metabolic pathway for elimination of chole from the body. (See Clinical Pharmacology.)

§The probable benefits obtained from $L D L$-chole reduction must be weighed against the possible ri of a reduction in $\mathrm{HDL}$-cholesterol when assessing response of each patient receiving treatment with Lorelco. If satisfactory lipid alteration is not achieve the drug should be discontinued. (See Precautions.) 


\section{LEVELS \\ THE BEGININING}

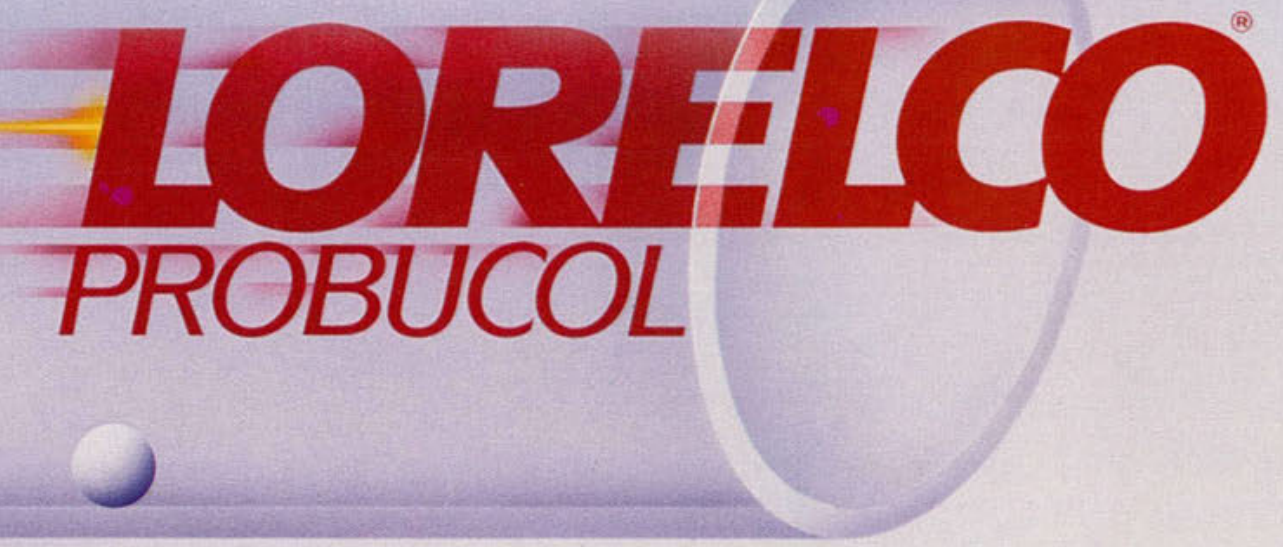

\section{Lorelco provides important patient compliance benefits}

- Convenient dosage - just one $500 \mathrm{mg}$ tablet b.i.d. with meals - Well tolerated-the most frequent side effect is loose stools, which occurs in about one in ten patients and generally subsides during continued therapy. See Prescribing Information for full discussion of side effects.

- Economical-can offer significant cost savings vs most other cholesterol-lowering therapies

Lorelco is not an innocuous drug and strict attention should be paid to the Indications, Contraindications, Warnings, and Precautions sections of Prescribing Information.

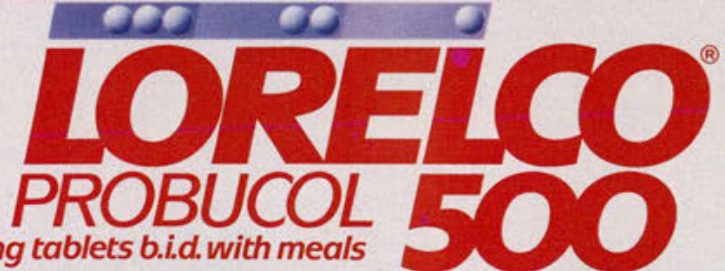

TAKES YOU TO THE NEXT LEVEL OF CHOLESTEROL CONTROL 



\section{Lorelco ${ }^{\circledR}$ Tablets (probucol)}

CAUTION: Federal law prohibits dispensing without prescription.

DESCRIPTION: Lorelco (probucol) film-coated tablets for oral administration contain $250 \mathrm{mg}$ or $500 \mathrm{mg}$ of probucol per

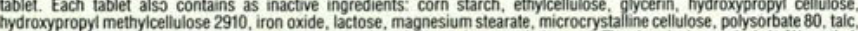
and ethylidene) bis(thio)]bis[2,6-bis(1,1-dimethylresemble that of any other available cho. lesterol-lowering agent. It is lipophilic.

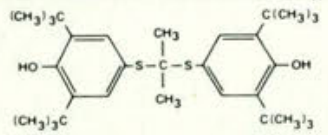

CLINICAL PHARMACOLOGY: Loreloc lowers total serum cholesterol and has relatively little effect on serum triglycerides. Patients responding to probucol exhibit a decrease in low-density lipoprotein (LOL) cholesterol. Cholesterol is reduced not only
in the LDL fraction, but also in the high-density lipoprotein $(\mathrm{HDL})$ fraction with proportionately greater effect on the high-density portion. Epidemioiogic studies have shown that both low $\mathrm{HDL}$-cholesterol and high $\mathrm{L} \mathrm{LL}$-cholesterol are independent risk factors or no effect reported on very low-density lipoprotein (VLDL).

Studies on the mode of action of Lorelco indicate that it increases the fractional rate of LDL catabolism. This effect may be linked to the observed increased excretion of ecal bile acids, a final metabolic pathway for the elimination of cholesterol from the body.
Lorelco also exhibits inhibition of early stages of cholesterol biosynthesis and slight inhibition of absorption of dietary



Absorption of Lorelco from the gastrointestinal tract is limited and variable. When it is administered with food, peak blood levels gradually increase over the first three to four months and thereafter remain fairly constant. in 116 patients treated with Lorelco or periods of three months to one year, the mean blood level was $23.6 \pm 17.2 \mathrm{mcg} / \mathrm{mL}( \pm S .0.) \mathrm{ranging}$ to $78.3 \mathrm{mcg} / \mathrm{mL}$. $1062.0 \mathrm{mcg} / \mathrm{mL}$. In a separate study in eight patients, blood levels averaged $19.0 \mathrm{mcg} / \mathrm{mL}$ at the end of $12 \mathrm{months}$ of the
Six weeks altter cessation of therapy, the average had fallen by $60 \%$. After six months, the average had tallen by $80 \%$. In December 1984, a National Institutes of Health Consensus Development Conference Panel1 concluded that lowering definitely coronary heart disease. The effect of probucol-induced reduction of serum cholesterol or triglyceride levels, or reduction of HDL-cholesterol levels on morbidity or mortality due to coronary heart disease has not been established.

INDICATIONS AND USAGE: Serious animal toxicity has been encountered with probucol. See WARNINGS and ANIMAL PHARMACOLOGY AND TOXICOLOGY sections. Probucol is not an innocuous drug and strict attention should be paid to the Drug therapy should not be used for the routine treatment of elevated blood lipids for the prevention of coronary heart disease.
Dietary therapy specific for the type of hyperlipidemia is the initial treatment of choice. Excess body weight may be an important factor and should be addressed prior to any drug therapy. Physical exercise can be an important ancillary measure. Contributory considered only when reasonable attempts have been made to obtain satistactory results with nondrug methods. II the decision
ultimately is to use drugs, the patient should be instructed that this does not reduce the importance of adhering to diet. The selection of patients for cholesterol-lowering drug therapy should take into account other important coronary risk tactors such as smoking, hypertension, and diabetes mellitis. Consideration should be given to the efficacy, saferty, and compliance Lorelco may be indicated for the reduction of elevated serum cholesterol in patients with primary hypercholesterolemia (Types control of diabetes mellitus. Lorelco may be useful to lower elevated Lol-cholesterol that occurs in those patients with control of diabetes mellitus. Lorelco may be useful to lower elevated LL-cholesterol that occurs in those patients with
combined hypercholesterolemia and hypertriglyceridemia (Type IIt) due to elevation of both LOL and VLDL, but it is nol indicated where hypertriglyceridemia is the abnormality of most concern. After establishing that the elevation in serum total cholesterol represents a primary lipid disorder, it should be determined that patients being considered for treatment with Lorelco
have an elevated LDL-cholesterol as the cause for an elevated total serum cholestero. This may be particularly relevant for patients with elevated triglycerides or with markedly elevated HDL-cholesterol values, where non-LDL fractions may contribute
significantly to total cholesterol levels without apparent increase in cardiovascular risk. In most patients, LDL-cholesterol may be estimated according to the following equation:

LDL-cholesterol $=$ Total cholesterol $-[(0.16 \times$ triglycerides $)+$ HDL-cholesterol $]$

When total triglycerides are greater than $400 \mathrm{mg} / \mathrm{dL}$, this equation is less accurate. In such patients, LOL-cholesterol may be

It is not always possible to predict from the lipoprotein type or other factors which patients will exhibit favorable results. Lipid

The effect of probucol-induced reduction of serum cholesterol or triglyceride levels, or reduction of HDL-cholesterol levels on morbidity or mortality due to coronary heart disease has not been established

CONTRAINDICATIONS: (See also WARNINGS and PRECAUTIONS.) Lorelco is contraindicated in patients who are known to CONTRAINDICATIONS: (See also WARNINGS and PRECAUn WNS.) Lorelco is contraindicated in patients who are known to
hane a hypersensitivity to it. Loretco is contraindicated in patients with evidence of recent or progressive myocardial damage or
findings suggestive of serious ventricular arithythmias or with unexplained syncope or syncope of cardiovascular origin.
Lorelco is contraindicated in patients with an abnormally long QT interval.

WARNINGS: SERIOUS ANIMAL TOXICITY HAS BEEN ENCOUNTERED WITH PROBUCOL IN RHESUS MONKEYS FED AN

Prolongation of the QT interval can occur in patients on Lorelco. Serious arrhythmias have been seen in association with an abnormally long QT interval in patients on Loreico alone an in

1. Patients should be advised to adhere to a low cholesterol, low fat diet at the start of treatment with Lorelco and throughout the

2. An ECG should be done prior to starting treatment and repeated at appropriate intervals during treatment. If an abnormally long QT interval is observed, the possible benefits and risks should be carefully considered betore making a decision to Lorelco therapy should be discontinued or not started if the OT interval at an observed heart rate on a resting ECG is
persistently more than one of the values listed below:

\begin{tabular}{ccc}
\multirow{2}{*}{$\begin{array}{c}\text { Observed Heart Rate } \\
\text { (beats/min) }\end{array}$} & \multicolumn{2}{c}{$\begin{array}{c}\text { QT Interval in } \sec (15 \% \text { above the } \\
\text { upper limit of normal) }\end{array}$} \\
\cline { 2 - 3 } & Males & Females \\
\hline 40 & 0.56 & 0.58 \\
50 & 0.52 & 0.53 \\
70 & 0.49 & 0.50 \\
80 & 0.45 & 0.47 \\
86 & 0.43 & 0.44 \\
92 & 0.42 & 0.43 \\
100 & 0.40 & 0.41 \\
109 & 0.39 & 0.40 \\
120 & 0.37 & 0.38 \\
133 & 0.36 & 0.36 \\
& 0.34 & 0.35
\end{tabular}

-Values calculated from Burch GE, Winsor T. A primer of electrocardiography. Philadelphia, PA: Lea and Febiger; 1958; p.
272 (Table 6).

3. Patients developing unexplained syncope or syncope of cardiovascular origin should have Lorelco therapy discontinued and

Drugs that prolong the $Q T$ interval are more likely to be associated with ventricular tachycardia after:
a. An increase in the dose of the drug.

Addition of a second drug that prolongs the OT interval (including tricyclic antidepressants, class I and III antiarrtiythmics. and phenothiazines).
Hypokalemia or hypomagnesemia.

c. Hypokalemia or hypomagnesemia.
d. Severe bradycardia due to intrinsic heart disease or drug effects on the atrial rate (beta-blockers) or AV block (digoxin)

The use of Lorelco in patients receiving any of these drugs should be based on the conclusion that tial benefits of cholesterol lowering outweigh the risk of serious arrhythmia.

The following conditions should be resolved or corrected prior to initiation of therapy with Lorelco:

a. Hypokalemia

c. Syporere bradycardia due to intrinsic heart disease or drug effects on the atrial rate (beta-blockers) or AV block (digoxin). d. Recent or act
PRECAUTIONS

General: Before instituting therapy with Lorelco, adequate baseline studies should be performed to determine that the patien has persistently elevated fotal and LLL-cholesterol levels representing a primary lipid disorder, and that the increased

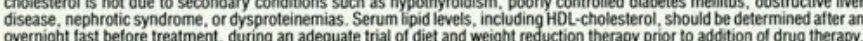

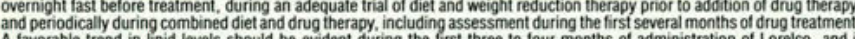
A tavorable trend in ilid levels should be evident during the first three to tour months of administration of Lorelco, and

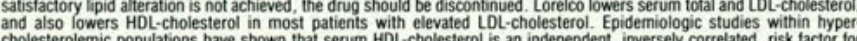
and also lowers $\mathrm{HDL}-$-cholesterol in most patients with elevated $\mathrm{LL}$-cholesterol. Epidermiologic studies within hyper-
cholesterolemic populations have shown that serum HDL-cholesterol is an independent, inversely correlated, risk tactor for
coronary heart disease (see CLINICAL PHARMACOLOGY. Human studies which will attempt to confirm or deny the hypothesis coronary heart disease (see CLINICAL PHARMACOLOGY). Human studies which will attempt to confirm or deny the hypothesis whether Loreloo-induced reduction of serum HDL-cholesterol will affect cardiovascular risk since no long-term, controlled
clinical trials of Loreico or tor the prevention of coronary heart disease, similar to the LRC-CPP ( see CLINICA. STUDIES, have reduction in HDL-cholesterol when assessing the response of each patient receiving Lorelco treatment. If satistactory lipid reduction in HOL-cholesterol when assessing the responss
alteration is not achieved, the drug should be discontinued.
Information for Patients: The patient should be instructed to adhere to a prudent diet. Females should be cautioned against with Lorelco.

Laboratory Tests: The physician should schedule periodic blood lipid determinations and periodic ECGs. (See WARNINGS. Elevations of the serum transaminases (SGOT, SGPT), bilirubin, alkaline phosphatase, creatine phosphokinase, uric acid, bloo urea nitrogen, and blood glucose above the normal range were observed ol one or more occasions in various patients ireates
with Lorelco. Most often these were transient and//or could have been related to the patient's clinical state or other modes therapy. Although the basis tor the relationship between Lorelco and these abnormalities is not firm, the possibility that some of these are drug related cannot te excluded. In controlled trials, the incidence of abnormal laboratory values was no higher in the patients treated with Lorelco than in the patients who received placebo. If abnormal laboratory tests persist or worsen, if clinica
signs consistent with the abnormal laboratory tests develop, or if systemic manitestations occur, Lorelco should be disconDrug Interactions: The addition of clofibrate to Lorelco is not recommended, since the lowering effect on mean serum level
of either LDL or total cholesterol is generally not significantly additive and, in some patients, there may be a pronounces is nor oral anticoagulants alter the effect of Lorelco on serum cholesterol. The dosage of these agents is not usualy modified when given with Lorelco.

Monkeys fed a high fat, high cholesterol diet admixed with probucol exhibited serious toxicity. (See WARNINGS and ANIMAL
PHABMACOLOGY AND TOXICOLOGY sections.) Prolongation of the Prolongation of the QT interval can occur in patients on Lorelco and serious drug that prolongs the QT interval (including tricyclic antidepressants, class I and III ant

Carcinogenesis, Mutagenesis, Impairment of Fertility

chronic studies of two years' duration in rats, no toxicity or carcinogenicity was observed. These results are consistent with Pregnancy

Pregnancy - Category B: Reproduction studies have been performed in rats and rabbits at doses up to 50 times the humar
Pose dose, and have revealed no evidence of impaired fertility or harm to the fetus due to probucol. There are, however, no adequate and well-controlled studies in pregnant women. Because animal reproduction studies are not always predictive of human
response, this drug should be used during pregnancy only it clearly needed. Furthermore, if a patient wishes to become pregnant, it is recommended that the drug be withdrawn and birth control procedures be used to
persistence of the drug in the body for prolonged periods. (See CLINICAL PHARMACOLOGY.)

Labor And Delivery: The effect of Lorelco on human labor and delivery is unknown.

Nursing Mothers: It is not known whether this drug is excreted in human milk, but it is likely, since such excretion has been Pediatric Use: Safety and effectiveness in children have not been established.

ADVERSE REACTIONS

Gastrointestinal
diarnhea or loose stools, flatulence, abdominal pain, nausea, vomiting, indigestion, gastrointestinal bleeding

Cardiovascular
prolongation of the OT interval on ECG. syncope, ventricular arrthythmias (ventricular tachycardia, torsades de pointes ventricular fibrillation), sudden deat

Neurologic

, paresthesia, insomnia, tinnitus, peripheral neuritis

Hematologic
eosinophilia, low hemoglobin and/or hematocrit, thrombocytopenia

Dermatologic
rash, pruritus, ecchymosis, petechiae, hyperhidrosis, tetid sweat

Genitourinary

impotency,

coniunctivitis, tearing, blurred vision

Endocrine
enlargement of multinodular goiter

Idiosyncrasies
observed with initiation of therapy and characterized by dizziness, palpitations, syncope, nausea, vomiting and chest pain diminished sense of taste and smell, anorexia, angioneurotic edema

DRUG ABUSE AND DEPENDENCE: No evidence of abuse potential has been associated with Lorelco, nor is ther

OVERDOSAGE: There is a single report of a $15-\mathrm{kg}$, three-year-old, male child who ingested $5 \mathrm{~g}$ of probucol. Emesis was
induced by ipecac. The child remained well, apart from a brief episode of loose stools and flatulence. No specific information induced by ipecac. The child remained well, apart from a briet episode of loose stools and tiatulence. No spectic informatio
is available on the treatment of overdosage with Lorelco and no specific antidote is available. Probucol is not dialyzable Ireatment is symptomatic and supportive. Probucol has shiown no identifiable acute toxicity in mice and rats. In thes
Inimals the L $\mathrm{O}$, (oral) is in excess of 5 g k kg of body weight. DOSAGE AND ADMINISTRATION: For adult use only. The recommended and maximal dose is $1000 \mathrm{mg}$ daily given wo divided doses of $500 \mathrm{mg}$ each (two $250 \mathrm{mg}$ tablets or one $500 \mathrm{mg}$ tablet) with the morning and evening meals.

HOW SUPPLIED: $250 \mathrm{mg}$ round, white, film-coated tablets imprinted with either the DOW diamond trademark over th $500 \mathrm{mg}$ capsule-shaped, white, film-coated tablets, marked LORELCO 500. Botties of 100 (NDC 0068-0053-61)

Keep well closed. Store in a dry place. Avoid excessive heat. Dispense in well-closed light-resistant containers with child ANIMAL PHARMACOLOGY AND TOXICOLOGY: In rhesus monkeys, administration of probucol in diets containin unusually high amounts of cholesterol and saturated fat resulted in the death of four of eight animals after several weeks

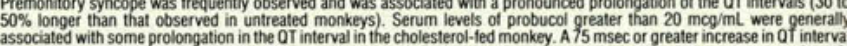
from control values was usually seen at $40 \mathrm{mcg} / \mathrm{mL}$ and above. Blood levels in humans receiving Lorelco average approximate)
$20 \mathrm{mcg} / \mathrm{mL}$ and not uncommonly reach levels of $40 \mathrm{mcg} / \mathrm{mL}$ and higher. Rhesus monkeys ted normal (low tat) chow an subjects. No adverse effects were detected in these monkeys over an eight-year period of continuous drug administration.

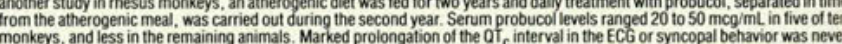
monkeys, and less in the remaining animals. Marked prolongation of the QT interval in the ECG or syncopal behivior was never
observed over the entire one-year treatment period. Regression of gross aortic lesions comparable to that observed in a paralle group of monkeys receiving cholestyramine was seen in animals receiving probucol. It should be emphasized that both $\mathrm{HO}$ cholesterol and L 2 -cholesterol were markedly reduced in this regression st
study involving 32 probucol-treated dogs (beagles), there were 12 tatalities. Subsequent experiments have indicated that probucol sensitizes the canine myocardium to epinephrine, resulting in ventricula
fibrilation in many dogs. Among the animal species in which probuccol has been studied the dog is peculiar with respect to the
phenomenon of sudden death due to the sensitization of the myocardium to epinephrine. In contrast to findings in the dog phenomenon of sudden death due to the sensitization of the myocardium to epinephrine.

In other studies, monkeys were given probucol either before and after, or only after myocardial intarction was induced b coronary artery ligation. In these studies, there was no difterence between probucol-and placebo-ite

Probucol has shown no identifiable toxicity in mice and rats. In these animals, the LDso (oral) is in From studies in rats, dogs, and monkeys, it is known that probucol accumulates slowly in adipose tissue. Approximately $90 \%$ probucol administered orally is unabsorbed. For that which is
the body and very little is excreted by way of the kidneys. Myocardial iniury was produced in various groups of rats by one of the following procedures: aortic coarctation, coronar
ligation, or cobalit or isoproterenol injection. After probucol administration, no deleterious effects related to treatment occurr
as measured by survival and microscopic examination of myocardial damage. Probucol was administered to minipigs beginning ten days before ligation of coronary artery and continued for 60 days afte surgery. Challenge with epinephrine at the end of 60 days tailed to induce ventricular fibrillation in any of the coronary-ligate

CLINICAL STUDIES: In a multicenter, randomized, double-blind study, the LRC-CPPT, ${ }^{3}$ hypercholesterolemic patient treated with an oral bile acid sequestrant (cholestyramine) and a cholesterol-lowering diet experienced average total and Lo
cholesterol reductions greater than those obtained in the placebo oroup treated with diet alone. The cumulative seven-yen cholesterol reductions greater than those obtained in the placebo group treated with diet alone. The cumulative seven-ye
incidence of the primary end point-combined incidence of definite $C$ HD death and/or definite nonfatal myocardial infarctionwas $7 \%$ in the cholestyramine group and $8.6 \%$ in the placebo group. This was a $19 \%$ reduction in risk (P less than 0.05 , single
tail test) of the primary end point reflecting a $24 \%$ reduction in definite CHD death and a $19 \%$ reduction in nonfatal myocardi

The subjects included in the study were middle-aged men ( $35-59$ years old) with serum cholesterol levels at least $265 \mathrm{mg} / \mathrm{dL}$ an no previous history of heart disease. It is no

The bile acid sequestrant, cholestyramine, was used in the above trial. Caution should be exercised in extrapolating these result to Lorelco since it differs from cholestyramine with regard to its mode of action, spectrum of cholesterol-lowering potenc, effect on HOL-cholesterol, and possible toxicity. The effect of probucol-ind
morbidity or mortality due to coronary heart disease has not been established.

REFERENCES

2. Fredrickson DS, Levye RI Panel. Lowering blood cholesterol to prevent heart disease. JAMA. 1985: 253-2080-2086.

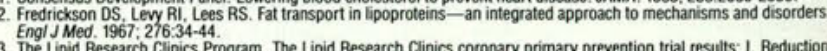
3. The Lipid Research Clinics Program. The Lipid Research Clinics
incidence of coronary heart disease. JAMA. 1984; 251:351-364.

Product Information as of June. 1988

MERRELL DOWUS.A.

Subsidiary of The Dow Chemical Company

Merrell Dow U.S.A. 9-1419(L0095)MDA067R May, 1989 Printed in U.S. 
Table 4

Topics for Presentation: Substance Abuse

Intravenous drug use

- Epidemiology of AIDS among IV drug users

- Women and AIDS

- Children and AIDS

- Use of safe needles

Substance abuse

- Effects of substance abuse on immunity

- Cofactors to AIDS

- AIDS-related diagnostic and treatment issues

- Review of relationship of substance abuse to AIDS

Secondary effect of alcohol and/or drugs on HIV transmission

- Effects of intoxication on safe sex practices (include alcohol and other drugs)

\section{Table 5}

Topics for Presentation: Psychosocial Complications

Social isolation and abandonment by family, friends, and significant others

- Changing body image and sexual issues

- Issues of death and dying

- Depression and suicide

- Discrimination (jobs, housing, etc)

- Prevention issues

- Management and treatment of psychosocial complications

1. Pharmacologic (antidepressants, anxiolytics, neuroleptics)

2. Psychotherapy (individual, group, family; supportive, insight-oriented, cognitive, etc)
Table 6

Topics for Presentation: Psychosocial Effects of Patient Care on Staff

- Staff attitudes toward groups at risk

- Staff stress in caring for dying patients

- Personal fears about job-related exposures
Topics for Presentation: Infection Control Issues

- Routes of transmission

- Hospital policy, guidelines, and procedures

- Universal precautions

- Risks to healthcare workers caring for infected patients

\section{Local and state health departments}

Health departments are a source for local and state epidemiologic data, such as total number of cases, risk-behavior characteristics, sex ratios, age distributions, etc. These departments also have access to national surveillance data from the Centers for Disease Control, which will make it possible to compare local data with national trends.

Local and state health departments often serve as clearing houses or lending libraries for other sources of information on HIV disease-videotapes, slide sets, etc.

\section{Medical or hospital libraries}

A hospital or medical library is one source for scientific journal articles. Many librarians can complete a computerized literature search to provide an extensive bibliography on any specific AIDS-related subject. Such a search could take several days. Most libraries also participate in an interlibrary loan program, making it possible to order articles that are not immediately available. It may take 2 weeks or more to obtain articles ordered via interlibrary loans. There may be a user charge for the literature search or the interlibrary loans; alternatively, the cost of the services may be borne by the hospital or library.

\section{Community library}

The community library has books, pamphlets, and magazine articles containing AIDS information that is commonly available to the public. For most scientific presentations, however, this resource is of limited use. 


\section{Local newspaper articles}

Reviewing local newspaper articles is an excellent way of finding out "current issues of concern," particularly those of a lay audience. After reading the articles, you may want to review relevant scientific literature to clarify (or correct) selected points.

\section{Prepare talk}

Several styles have evolved for preparing a talk. Many speakers, particularly those less familiar with the material, will write out their talks word for word. Others will prefer to use comprehensive outlines. Still others will use a combination of these techniques. Whatever the method, the specific content of the lecture should be clearly identified and an organized, logical format developed for its presentation. It is far better to be clear and concise and finish the talk a few minutes early than to prolong the talk when there is little more of value to say. Any extra time can be used for questions.

\section{Develop audiovisual aids}

Audiovisual aids are a critical component of an interesting presentation. For a formal presentation to a large audience, $35-\mathrm{mm}$ slides work well. Slides can be expensive if made commercially, though many hospitals, colleges, and universities have special arrangements for producing them at a minimal fee or at no charge.

An overhead projector with transparencies can work well for groups of any size. The transparencies can be prepared ahead of time, with text and drawings. Special multicolored permanent marking pens are available for overhead slides. Erasable pens can be used to highlight certain areas during the presentation. Transparencies have several advantages: they are inexpensive and can be made without ancillary audiovisual services, and eye contact with the audience is easily maintained. Some modern copy machines can make overhead transparencies from drawings and other prepared material.

Other visual aids might include videotapes, movies, brochures, and tape recordings; the range seems endless. Also, a simple outline of the presentation could be provided to each participant for note taking.

\section{Give a good presentation}

Many dos and don'ts have been given for making a good presentation. For example, you should view the audience as a group of friends, as persons who want to hear what you have to say. In a friendly ambience, you will be able to give your presentation without undue anxiety. Additional suggestions are given in Table 9.

\section{Prepare for questions}

The audience will appreciate time for questions and may even demand time if it is not scheduled. When AIDS is the topic, questions can be diverse. Even with a "scientific" audience of healthcare workers, questions can seem more emotional than scientific. Many controversies have surfaced with respect to the disease: the obligation to treat patients with any disease versus the right to refuse care; the right to demand HIV testing on each hospital admission versus voluntary consent; required HIV testing of physicians versus voluntary consent; confidentiality versus the duty to inform. These conflicting viewpoints are accompanied with emotions about the disease and the persons it most affects, gay men and intravenous drug users. With the increase in heterosexual transmission, the fears only grow stronger. AIDS hysteria can be real, and it may be reflected in the audience's questions.

Each of us has feelings about HIV disease. These may be very intense and even in direct opposition to the facts about the disease. Little is gained by a speaker's being defensive. In answering a question, a diplomatic response can be helpful, even if it does not address the issue in detail. Often those who ask questions are not so much asking questions as providing their own opinions on or their understanding of a particular topic. An appropriate response might be, "There are many perspectives," or "That is an interesting concept." In response to a question that is long or cumbersome or does not seem relevant to the audience, you 
Table 9

Some Dos and Don'ts for HIV Disease Presentation

Dos

- Know your audience

- Make an outline

- Narrow topics to be included in presentation

- Be familiar with relevant current newspaper and journal articles

- Use readable audiovisual materials

- Look at your audience

- Keep within allotted time

- Allow time for questions

- Speak clearly and slowly

- Define terms audience may not know

- Summarize material

Don'ts

- Don't try to cover all aspects of subject

- Don't exceed allotted time

- Don't read long lists of numbers and statistics

- Don't mumble, do speak loudly

- Don't be too technical or too simplistic, aim to speak at audience's level of comprehension might suggest, "Perhaps we can best talk about that after the presentation." This, however, will obligate you to stay afterward to discuss the issue. If you do not know the answer to a question, frequently the best response is, "I don't know." To this you could add an offer to find out the answer and contact the questioner, perhaps by making a short telephone call or sending the person a journal article.

Frequently, questions are related to a recent newspaper or journal article. Members of the audience may want an "expert opinion" (your opinion) on something they have read or heard. A familiarity with current newspaper and journal articles will help you to clarify these issues for the audience.

\section{Conclusions}

As AIDS education continues to be the primary means of controlling the spread of the epidemic, osteopathic physicians will increasingly be asked to give presentations on HIV disease. The general guidelines offered in this paper will help you to prepare for an AIDS presentation.

\section{Suggested readings}

American Psychiatric Association: The AIDS Primer. Washington, DC, American Psychiatric Association, 1989.

Barnish MI, Condoluci DV: New Jersey's approach to AIDS. JAOA 1988;88:1091-1094.

Calabrese LH, Kelley D: The physician's role in the prevention of AIDS. JAOA 1988;88:877-890.

Campbell RC: AIDS: The general practitioner's concern. JAOA 1988;88:371-380.

Dekker AH: The impact of AIDS in the pediatric and adoles1cent populations. JAOA 1988;88:629-633.

Guidelines for effective school health education to prevent the spread of AIDS. MMWR 1988;37(suppl 2):1-14.

Gulick PG: Review of current therapy in human immunodeficiency viral infections. JAOA 1988;88:998-1002.

HIV/AIDS Surveillance, published by the Centers for Disease Control, Atlanta; updated monthly.

Human immunodeficiency virus (HIV) infection codes official authorized addendum (ICD-9-CM) (revision No. 1). MMWR 1987;36(suppl 7):1S-20S.

Human immunodeficiency virus (HIV) infection in the United States: A review of current knowledge. MMWR 1987; 36(suppl 7).

Johnson JM: AIDS-related psychosocial issues for the patient and physician. JAOA 1988;88:234-238.

Johnson JM: Neuropsychiatric sequelae of HIV infection. JAOA 1988;88:494-498. Kane WM: The physician and AIDS education in the schools. JAOA 1988;88:634-636.

Krachman S, D'Alonzo GE Jr: Acquired immunodeficiency syndrome and the health care worker. JAOA 1988;88:749-754.

Public Health Service guidelines for counseling and antibody testing to prevent HIV infection and AIDS. MMWR 1987;36(suppl 2):505S-519S.

Recommendations for prevention of HIV transmission in health care settings. MMWR 1987;36(suppl 2):1S-18S.

Revision of the CDC surveillance case definition for acquired immunodeficiency syndrome. MMWR 1987 (suppl 1):1S-15S.

Theriault RL: Acquired immune deficiency syndrome: An overview. JAOA 1988;88:109-113.

Update: Acquired immunodeficiency syndrome--United States, 1981-1988. MMWR 1989;38(14):229-236. 


\section{The National Osteopathic Foundation Announces:}

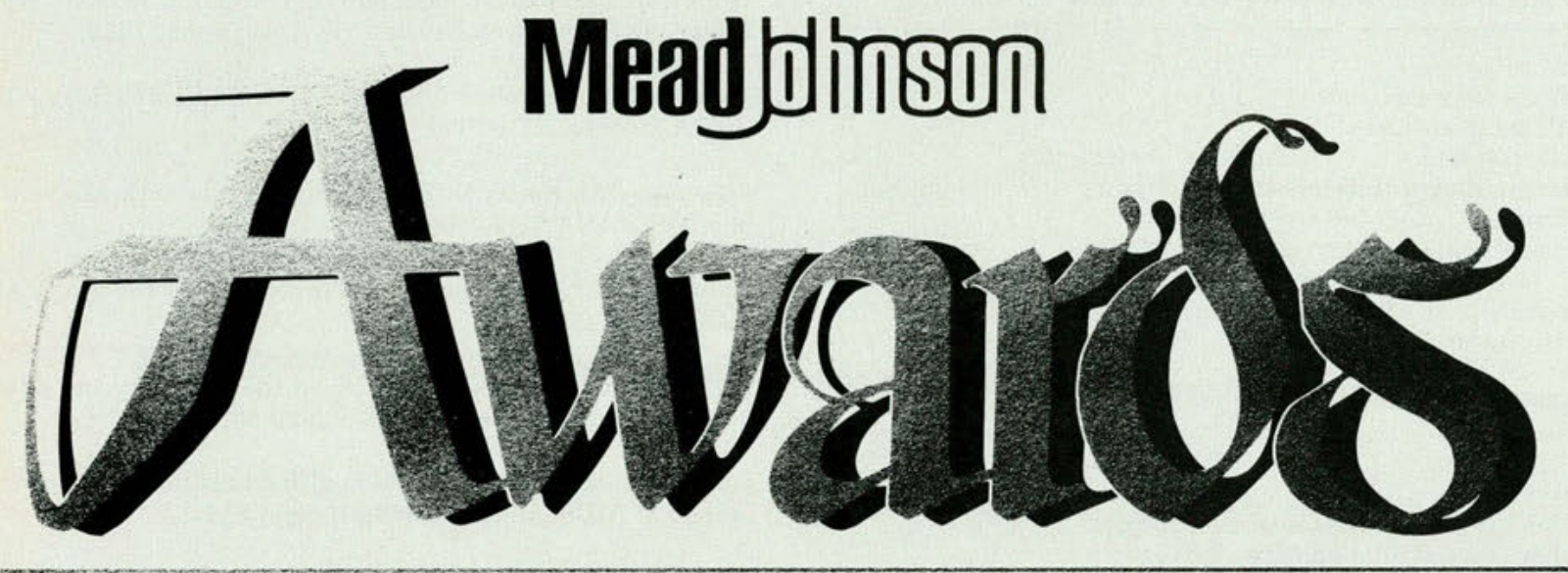

\section{FOR GRADUATE TRAINING}

Six $\$ 5,000$ awards in 1990 plus round trip transportation to AOA annual meeting.

Award recipients will be the guests of honor at an awards breakfast to be hosted by Mead Johnson at the AOA Annual Meeting

- For residency training in AOA approved specialties

The National Osteopathic Foundation administers all funds and selection of recipients

The Mead Johnson Awards for Graduate Training in osteopathic medicine provide financial assistance to selected graduates toward completion of a year of residency training. Mead Johnson has participated by providing funds for this joint endeavor since 1956.

Grants are available to any osteopathic physician within four years of date of graduation from an osteopathic college. The recipient may choose any hospital approved for residency training by the American Osteopathic Association.

Application forms may be obtained by writing to:

Committee on Educational Grants

The National Osteopathic Foundation

142 E. Ontario, 2nd Floor

Chicago, Illinois 60611

(800) 621-1773 (Ext. 5850) 